\title{
Hydrodynamic cavitation for lignocellulosic biomass pretreatment: a review of recent developments and future perspectives
}

\author{
Thiago Averaldo Bimestre ${ }^{1 *} \mathbb{D}$, José Antonio Mantovani Júnior ${ }^{2}$, Eliana Vieira Canettieri ${ }^{1}$ and \\ Celso Eduardo Tuna'
}

\begin{abstract}
The hydrodynamic cavitation comes out as a promising route to lignocellulosic biomass pretreatment releasing huge amounts of energy and inducing physical and chemical transformations, which favor lignin-carbohydrate matrix disruption. The hydrodynamic cavitation process combined with other pretreatment processes has shown an attractive alternative with high pretreatment efficiency, low energy consumption, and easy setup for large-scale applications compared to conventional pretreatment methods. This present review includes an overview of this promising technology and a detailed discussion on the process of parameters that affect the phenomena and future perspectives of development of this area.
\end{abstract}

Keywords: Hydrodynamic cavitation, Lignocellulosic biomass, Pretreatment, Hydrodynamic cavitation reactor, Biorefinery

\section{Introduction}

With high population growth rates, the global population should reach 9.7 billion by 2050 with estimated energy consumption of 851 quadrillion BTU in 2040 (Bhowmick et al. 2018). Associated with quick global economic development arises with the concern of power supply in the next decades and with the increased demand for fuel and chemicals. With the strong dependency of the international power system for fossil fuels and the preoccupation of sources depletion, global climate changes and negative impact on the people's health due these sources are clear the necessity of alternative energy resources, sustainable with clean and renewable raw materials (Mahmood et al. 2019). In this sense, extensive research has been done to develop biotechnological routes of low environmental impacts that use lignocellulosic biomass

\footnotetext{
*Correspondence: thiagobimestre@hotmail.com

${ }^{1}$ Chemistry and Energy Department, School of Engineering, São Paulo

State University UNESP, Guaratinguetá, SP 12516-410, Brazil

Full list of author information is available at the end of the article
}

residual abundantly generated throughout in the agricultural and forestry sectors to bioenergy, biofuel, and bioproducts production (Madison et al. 2017). However, due to the complex structure and recalcitrance of lignocellulosic biomass, a pretreatment step is required to make its use viable.

In this path, hydrodynamic cavitation arises as a promising technological route to lignocellulosic biomass pretreatment (Wu et al. 2019). Hydrodynamic cavitation phenomena occur through mechanical constrictions as Venturi pipes, orifice plates, and throttling valve, which cause a sufficient pressure change to form vapor microcavities that collapse releasing high energy amount, inducing physical and chemical transformations, which favor the lignin-carbohydrate matrix disruption (Bimestre et al. 2020). Although the use of hydrodynamic cavitation as a pretreatment of lignocellulosic biomass has been studied for some time, the number of published articles is relatively small (less than 35 ) compared to other emerging pretreatment methods, indicating that $\mathrm{HC}$ did not attract much attention of researchers (Sun et al. 2021a). 
This review discusses the recent developments over hydrodynamic cavitation for the lignocellulosic biomass waste pretreatment, beyond the influence parameters of these phenomena and perspectives of future development on this area.

\section{Lignocellulosic biomass and pretreatment step}

Lignocellulosic biomass is grown as an energetic culture and does not compete with food cultures (Ji et al. 2020).

The lignocellulosic waste is commonly divided into two classes: residues abandoned in the field after the harvest and residues detached from industrial procurement. Usually, part of the lignocellulosic waste is destined to boilers in the power production at agricultural industries, however, has a large available surplus, which if not properly disposed of can bring significant environmental problems (Zuin et al. 2018). Thus, lignocellulosic biomass conversion provides, besides a renewable energy source, offers a reduction of excessive waste accumulation during processing. The generation of lignocellulosic waste in the world is estimated to be over 13 billion tons per year (Arias et al. 2021), which would be readily available to produce a range of higher value-added products as biofuels, power, and chemicals, reinforcing the biorefinery concept (Hassan et al. 2018).

The lignocellulosic biomass is composed of cellulose, hemicellulose, and lignin in addition to extractives in smaller proportions. One of the principal compounds of the vegetable biomass cell wall is cellulose, which is a linear polysaccharide with repetitive units named cellobiose (disaccharide D-glucose) that are joined by $\beta-(1 \rightarrow 4)$ bonds. Strong intramolecular or intermolecular hydrogen bonds occur through free hydroxyl $\mathrm{OH}$ groups of cellulose molecules. The intramolecular bond occurs between hydroxyl groups of the same molecule, giving it a certain stiffness. The intermolecular bond on the other hand occurs between hydroxyl groups of adjacent chains responsible for fibril formation and ordered structures, which are accountable for generating cellulose fibers (Sharma et al. 2019). The cellulose molecules are extremely solid and low reactive, with a high degree of polymerization and cristanility (polymerization degree of 500-15,000) having crystalline and amorphous regions; so that for cellulose solubilization degradation of fibril structures is necessary, breaking intermolecular bonds and obtaining glucose as a product (Kleingesinds et al. 2018).

Hemicellulose is a random heterogeneous and branched polymer, composed of different polysaccharides (poliosis) and includes pentoses (xylose and arabinose), hexoses (glucose, galactose, and mannose), and uronic acids. The branched nature of hemicellulose allows the formation of strong bonds with cellulose (hydrogen bonds) and lignin (covalent bonds) that increase the lignocellulosic material stiffness. Furthermore, hemicellulose has different sugar units that are linked together, does not form a fibrous arrangement as cellulose, and has amorphous regions. The hemicellulose has a low polymerization degree (DP 50-200) (Koupaie et al. 2019). Different types of hemicellulose can be found in nature, which is composed of different polymers, e.g., xyloglucans, xylans, and mannanas, of which xylan is more abundant. The xylans can be classified in homoxylans, arabinoxylans, glucuronoxylan, and arabinose glucuronoxylan, the last one is the main component of agricultural residue (Banerjee et al. 2019). Lignin is a big and complex compound, made of phenylpropane units that are bonded in a three-dimensional structure.

The main lignin monomers are the cumarylic alcohol (p-Hydroxyphenyl), the coniferyl, and synapse alcohols (Renault et al. 2019). Lignin acts as a "glue" that joins cellulose and hemicellulose to form a three-dimensional stiff structure cell wall of plants. These features turn lignin into the most resistant lignocellulosic biomass component to chemical and biological degradation (Zheng et al. 2014). If the lignin content is high, higher is the degradation resistance (Li et al. 2018).

Due to the complex structure of lignocellulosic biomass, its use without a pretreatment step results in lower sugar yields in biorefineries. Hence the complex lignocellulosic matrix's highly recalcitrant deconstruction presents itself as the main challenge to be surpassed through the pretreatment step. The pretreatment step aims to open the recalcitrant structure of lignocellulosic material, providing an easier action of enzymes at a later stage of enzymatic hydrolysis, favoring the recovery of monomer sugars that are present in the carbohydrate fractions for later use in bioprocesses (Luo et al. 2021; Verdini et al. 2021). A successful pretreatment step should promote the biomass delignification, modifying and/or removing hemicellulose, decrease the crystallinity degree of cellulose, and increase the surface area and porosity, thus increasing the digestibility extension. In addition, it should limit the production of inhibitors, reduce production costs and the energy demand (Kumari and Singh 2018; Ponnusamy et al. 2019; Rezania et al. 2020; Zheng et al. 2014; Sun et al. 2021a).

The pretreatment of lignocellulosic material can be classified as physical, chemical, physical-chemical, biological, or a combination of these, which will depend on the required separation degree and of the proposed end (Lee and Park 2020) (Kumar and Sharma 2017). Through the physical pretreatment methods can highlight milling, extrusion, freezing, and microwave irradiation. These methods decrease the particle size and increase the superficial lignocellulosic material area but 
are not effective in isolation and are employed combined (Kumari and Singh 2018). Among the chemical pretreatment methods can highlight organosolv, ozone, and ionic liquids methods. The acid and alkaline methods are the most extensively employed due to providing high cellulose and hemicellulose solubilization and lignin removal.

Acid pretreatment methods are performed at low concentrations with high temperatures; furthermore, specific equipment must work in severe chemical conditions to avoid reactor corrosion. Differently, the alkaline pretreatment can be performed with low temperatures with long residence time, although have high water consumption to wash the pretreated biomass, which is not environmentally friendly (Haldar and Purkait 2021). The physical-chemical pretreatments are ammonia fiber explosion (AFEx), autohydrolysis or steam explosion pretreatment, liquid hot water (LWG), wet oxidation (WO), and ultrasonication (US) (the US is a physical pretreatment used for pretreating lignocellulosic biomass for their conversion to bioproducts but when the US is used with an acid or base it can be called a physicochemical pretreatment) (Abraham et al. 2020). The biological methods most employed are fungal (Giri and Sharma 2020) microbial, and enzymatic (Rai et al. 2019). Detailed information on emerging technologies for pretreating of lignocellulosic biomass can be found in many reviews such as (Yiin et al. 2021; Mankar et al. 2021; Kumar et al. 2020; Sarker et al. 2021).

The generation of hazardous environmental waste and/ or high energetic inputs are the bottleneck of lignocellulosic biomass pretreatment processes and there is an urgent need for green technological solutions for this challenge (Ong et al. 2021).

\section{Hydrodynamic cavitation}

The cavitation phenomena occur when vapor microbubbles are formed in a liquid flow, grow and then collapse due to sudden reductions of local pressure. Based on generation modes the cavitation is classified into four types: acoustic, hydrodynamic, optic, and particle. Meanwhile, only acoustic and hydrodynamic cavitation was efficiently considered in physical-chemical change production which is desired in pretreatment processes (Thanekar and Gogate 2019; Li et al. 2020). The acoustic cavitation is obtained by propagating an ultrasonic signal $(20-100 \mathrm{kHz})$ of high amplitude in a liquid being the most frequent way to produce cavitation on a laboratory scale (Hilares et al. 2017a).

Hydrodynamic cavitation is more efficient than acoustic cavitation in many applications due to its capacity to oxide organic substances allied to low-cost operation, easy scalability, high power efficiency, and less polluting with no byproducts formed (Raut-Jadhav et al. 2016;
Nakashima et al. 2016). Figure 1 shows a hydrodynamic cavitation reactor and its components as well as some cavitation device options.

It is produced through mechanical constrictions, such as Venturi pipes, orifice plates, and throttling valves. The cavitation can be explained based on the velocity-pressure fluid relationship in agreement with Bernoulli's equation. When fluid flows through the constriction the pressure falls below the liquid-vapor pressure with flow temperature, then form vapor cavities, which collapse in the downstream region and create highly destructive shockwaves with huge pressures, vigorous turbulence, and generate strain (Badve et al. 2013). This collapse is sufficiently strong to release large energy amounts in a short space (Shrikant and Khambete 2017). The vapor cavity implosion can locally generate high temperatures of 5000-10,000 K and pressures of 1000-2000 atm, which induces physical and chemical transformations, producing strong oxidative radicals such as the hydroxyl radical $(\mathrm{OH}-)$ due to water molecules decomposition and organic molecules decomposition/pyrolysis trapped inside or nearby vapor cavities contributing to structural disintegration and biomass porosity increase (Kim et al. 2015). Concerning vapor bubbles, dynamic exists two main features: the maximum size bubble and its traveled distance before the collapse, i.e., its useful life. After vapor bubbles form, an expansion process begins due to quick liquid vaporization. If during the expansion process the vapor bubbles are submitted to a pressure higher than vapor pressure, its development is interrupted, the interior bubble pressure increases, and vapor condensation initiate resulting in bubble collapse. As the specific vapor volume is greater than the specific liquid volume the collapse will create void provoking shockwaves. The maximum bubble size defines the cavitation intensity. Bubbles grow under low pressure or high temperature, and larger bubbles implode with greater intensity and can generate more effects on a substance than smaller bubbles (Madison et al. 2017). Hydrodynamic cavitation can also be produced by an object mechanical rotating through a liquid, occurring in the centrifugal pump inlet and hydraulic turbine rotor outlet. Although it is an undesired phenomenon in hydraulic machinery areas, hydrodynamic cavitation is being applied in water and effluent treatment (Abramov et al. 2021; Sun et al. 2021a; Wang et al. 2020), biogas production (Zielinski et al. 2019; Saxena et al. 2019; Patil et al. 2016), cell disruption (Mevada et al. 2019), biodiesel production (Samani et al. 2021; Chipurici et al. 2019; Chitsaz et al. 2018), microalgae oil extraction (Waghmare et al. 2019; Lee et al. 2019), chemical reactors (Dhanke and Wagh 2020) and lignocellulosic biomass pretreatment (Thangavelu et al. 2018; Hilares et al. 2019). 


\section{a Hydrodynamic Cavitation Reactor}

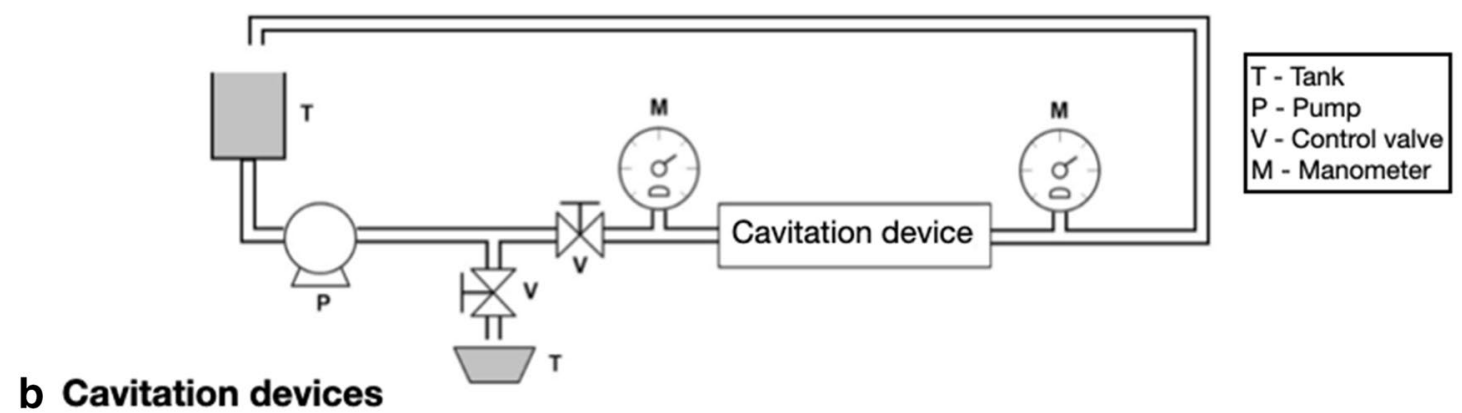

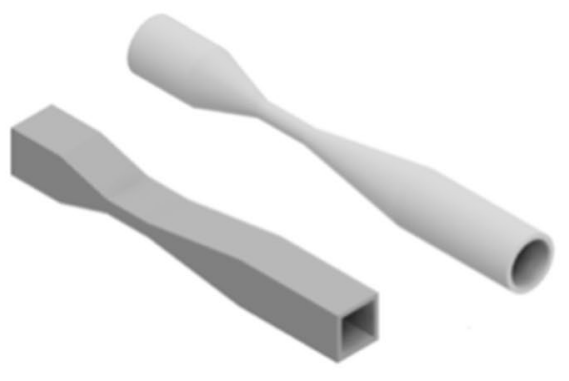

- Venturi tube reactors

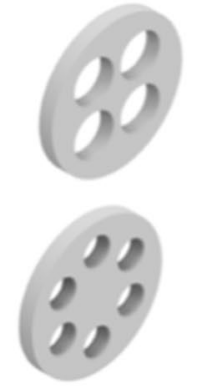

- Orifice plates

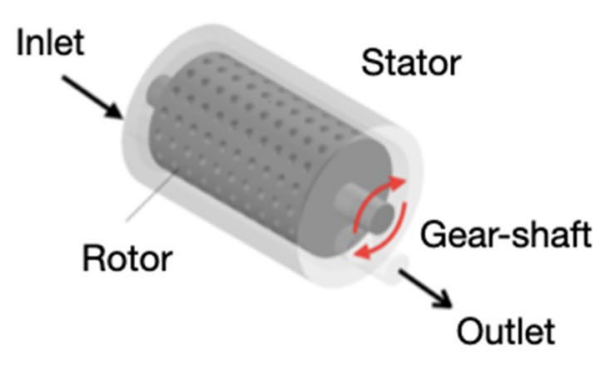

- Rotor-stator reactor

Fig. 1 Schematic diagram of different HC systems

\section{Hydrodynamic cavitation reactors}

Hydrodynamic cavitation reactors are divided into two categories: non-rotating reactors, such as orifice plates or Venturi pipes and rotating reactors, where cavitation is generated on a region swept by high-velocity propellers (Sun et al. 2018a). Hydrodynamic cavitation reactor can also be categorized based upon its operating ways, as a pulsating hydrodynamic cavitation reactor (operating the reactor in cycles); continuous hydrodynamic cavitation reactor, and a shear-induced hydrodynamic cavitation reactor (Panda et al. 2020).

\section{Non-rotational hydrodynamic cavitation reactors (NRHCRs)}

The NRHCRs consist of a feed tank, a pump that makes circular mixture reactions through the reactor (cavitation chamber) as well as control valves, pressure transducers, and temperature gauge.

The Venturi pipe is composed of three sequential parts: a convergent section (nozzle), a throat, and a divergent section (diffusor). It can present circular or polygonal cross sections depending on the application and is historically applied to measure and to control the flow rate inflows, and recently is being employed in gas purification systems (Bal et al. 2019) solid-gas injectors (Jensen et al. 2018), jet hydraulic pumping (Ji et al. 2015) and hydrodynamic cavitation reactors (Simpson and Ranade 2019).

Orifice plates are simple, robust, relatively easy, and low cost to manufacture, instruments compared with venturi pipes. In an orifice plate reactor, the fluid flow follows through one or more constrictions in such a way that with a flow area decrease occurs a sudden velocity increase leads to pressures below liquid vapor pressure resulting in cavitation. When fluid flow passes by the orifice a flow reconfiguration occurs, which is named vena contracta. By that of Li et al. (2019), the Venturi pipes outperform orifice plates in disinfection applications with excellent performance in bacterial clusters generating denser cavitation and with more vapor bubbles formed. Moreover, Venturi pipes present higher flow rates than orifice plates to the same inlet energy leading to a greater treatment capacity and energetic efficiency, despite the higher manufacturing cost. Besides, in Venturi pipe systems with high solid load can be needed the use of special pumps as the diaphragm and helicoidal pumps with relatively higher costs than usual centrifugal pumps. For Saharan (2016), the pressure recovers smoothly in Venturi pipes due to the divergence angle leaving vapor cavities with enough time to grow to maximum size, increasing collapse intensity and the yield of cavitation, which does not occur in orifice plates. In the design of hydrodynamic cavitation, reactor is needed to consider 
some vital parameters in the process and the influence comprehension of these parameters in involved physical and chemical mechanisms. An important and widely used parameter to evaluate and optimize the hydrodynamic cavitation reactor performance is a dimensionless quantity known as cavitation number given as:

$$
\sigma_{c}=\frac{P_{2}-P_{v}}{0.5 \rho U^{2}}
$$

where $P_{2}$ is the recovered pressure downstream of the cavitation device $(\mathrm{Pa}), P_{\mathrm{v}}$ is the vapor pressure of the liquid at the operating temperature $(\mathrm{Pa}), \rho$ is the density of the solution $\left(\mathrm{kg} / \mathrm{m}^{3}\right)$ and $U$ is the velocity at the constriction $(\mathrm{m} / \mathrm{s})$. The critical cavitation number corresponds to $\sigma_{c}=1$, i.e., the number, where cavitation initiates. Under ideal conditions, cavitation occurs when $\sigma_{c}<1$. Minimum cavitation number values result in more bubble generation and consequently increase the phenomenon intensity (Ijiri et al. 2018). However, it can be observed that the cavitation number does not consider local fluid dynamics. Therefore, the cavitation number is not a suitable parameter to compare the geometrical efficacy of cavitation devices (Dastane et al. 2019). A parameter called Cavitation Efficacy Ratio (CER) can be used to fix this problem. The CER is defined as follows:

$$
\mathrm{CER}=\frac{P_{\text {collapse }}}{P_{1}-P_{2}}
$$

where $P_{\text {collapse }}$ is the generated pressure after cavity collapse $(\mathrm{Pa}), P_{1}$ is the inlet pressure $(\mathrm{Pa})$ and $P_{2}$ is the outlet pressure $(\mathrm{Pa})$. Essentially, the CER is the maximum theoretical efficacy of a cavitation system, where the collapse pressure represents the maximum energy amount that can be released by a cavity in a determined flow field, and the denominator is the permanent pressure loss (dissipated energy) during the process. The CER values can be useful to estimate the physical effects extension of cavitation. A cavitation device comparison based on CER can be directly applied to select cavitation devices (Dastane et al. 2019). The collapse pressure is determined by empirical correlation proposed by Gogate and Pandit (2001), which is easy-to-use and valid across the entire parameters range that commonly are employed in hydrodynamic cavitation applications (initial cavity size of 0.01-0.1 mm, inlet pressure of 1-8 atm, orifice diameter of $1-10 \mathrm{~mm}$ and holes free area percentage of $1-20 \%$ ). The final developed correlation to hydrodynamic cavitation is given by the following:

$$
P_{\text {collapse }}=7527 .(A)^{-2.55}\left\{\left(P_{i}\right)^{2.46}\left(r_{0}\right)^{-0.8}\left(d_{0}\right)^{2.37}\right\}
$$

where $P_{\text {collapse }}$ is the bubble collapse pressure (atm), $A$ is the holes free area percentage (\%), $P_{i}$ is the inlet pressure (atm), $r_{0}$ is the initial cavities radius $(\mathrm{mm})$ and $d_{0}$ is the cavitation device diameter $(\mathrm{mm})$. The correlation is only an indication of collapse pressure magnitude in hydrodynamic cavitation reactor. Another important parameter to consider in hydrodynamic cavitation reactor design is the cavitational yield developed by Gogate and Pandit (2001) expressed as:

$$
\text { Cavitational yield }=K .\left(P_{\text {collapse }}\right)^{w}
$$

where the constant $K$ and exponent $w$ rely on reactor geometry, operational parameters and reaction type, which is being realized.

Despite the wide use of non-rotational reactors in numerous applications due to their structural versatility and ease of use, their effectiveness was considered unsatisfactory as they present considerable pressure losses due to severely restricted flow (Šarc et al. 2018; Tasalagkas et al. 2021).

\section{Advanced rotational hydrodynamic cavitation reactors (ARHCRs)}

The rotational reactors are based on centrifugal pumps, which have a modified rotor and a stator added in their housing (Kumar and Pandit 1999). In this type of reactor, the cavitation phenomenon is generated by numerous cavitation generation units (CGUs) located on the rotor and stator. A geometric structure of the CGUs is fundamental for the generation of cavitation as well as the effectiveness and economic efficiency. Furthermore, the frequency of energy release is significantly higher compared to NRHCRs (Sun et al. 2020a). Rotational reactors have exhibited excellent performance compared to non-rotational reactors for delignification (Lauberte et al. 2021), water treatments (Gostiša et al. 2021), biodiesel production (Samani et al. 2021), and sludge disintegration (Kim et al. 2020).

Researches investigating ARHCRs by experimental flow visualization (Kosel et al. 2019; Petkovšek et al. 2013; Šarc et al. 2018), computational fluid dynamics (Badve et al. 2015), and the characteristic experiment (Sun et al. 2018b, 2020b, 2021b) were presented to understand the mechanisms and design criteria of ARHCRs.

The effects of cavitation generation units (CGUs) on the performance of ARHCRs must be studied using computational fluid dynamics evaluating the effects of shape, diameter, interaction distance, height, and inclination angle of a CGU on the amount of cavitation generation and energy consumption of a representative ARHCR (Sun et al. 2021c).

To further improve the performance and develop the design criteria of the ARHCRs, a multi-objective 
optimization in the ARHCR framework is required. Sun et al. (2021d) performed for the first time a multiobjective optimization combining genetic algorithm (GA) and CFD. The chosen objectives were to minimize energy consumption and maximize the generation of hydrodynamic cavitation (Sun et al. 2021d).

To evaluate the thermal performance of ARHCRs, two important parameters are proposed by Sun et al. (2020b): Heat generation rate (HGR) and thermal efficiency (TE). The HGR produced by the ARHCRs is defined as the following:

$$
\mathrm{HGR}=\rho_{\text {out }} \cdot Q_{\text {out }} \cdot C_{p} \cdot \Delta T
$$

where HGR is heat generation rate in $M J / h, Q_{\text {out }}$ is the outlet flow rate, $\mathrm{m}^{3} / \mathrm{h}, \mathrm{C}_{\mathrm{p}}$ is the specific heat of fluid, $\Delta T=T_{\text {out }}-T_{\text {in }}$, in ${ }^{\circ} \mathrm{C}$, and $\rho_{\text {out }}$ is the outlet fluid density in $\mathrm{kg} / \mathrm{m}^{3}$, defined as:

$$
\rho_{\text {out }}=1000-0.0178 x\left|T_{\text {out }}-4\right|^{1.7}
$$

The thermal efficiency (TE) according to Sun et al. (2020b) is defined as:

$$
\mathrm{TE}=\frac{\mathrm{HGR}}{3.6 x P_{S}}
$$

where $P_{\mathrm{s}}$ is the measured shaft power of the electric motor in $k W$.

The cavitation index, $\sigma_{c}$, is defined as:

$$
\sigma_{c}=\frac{P_{\text {out }}-P_{\mathrm{v}}}{0.5 \rho \cdot\left(V_{\text {in }}+V_{\text {tangential }}\right)^{2}}
$$

where $P_{\text {out }}$ and $P_{\mathrm{v}}$ are the outlet static and saturated vapor pressures in $\mathrm{Pa}$, respectively, $V_{\text {in }}$ is the inlet velocity in $\mathrm{m} / \mathrm{s}$ and $V_{\text {tangential }}$ is the tangential velocity at the side of the rotor and can be calculated by:

$$
V_{\text {tangential }}=\frac{\pi \cdot d \cdot \omega}{6}
$$

where $d$ is the rotor diameter in $\mathrm{m}$ and $\omega$ is the rotational speed in rpm.

\section{Hydrodynamic cavitation applied to lignocellulosic biomass pretreatment}

The effects of hydrodynamic cavitation can enhance the pretreatment of lignocellulosic biomass and contribute to delignification and subsequent hydrolysis of carbohydrates. Figure 2 illustrates the lignocellulosic biomass pretreatment via the hydrodynamic cavitation approach.

A recent literature review of hydrodynamic application as lignocellulosic biomass pretreatment is presented in Table 1 highlighting the process parameters, reactor type and the main results obtained in each study.

The first studies on hydrodynamic cavitation applied to lignocellulosic biomass pretreatment date from 2012 and were conducted by Baxi and Pandit (2012). In this study, hydrodynamic cavitation was used for the delignification of wood. The sawdust was treated with

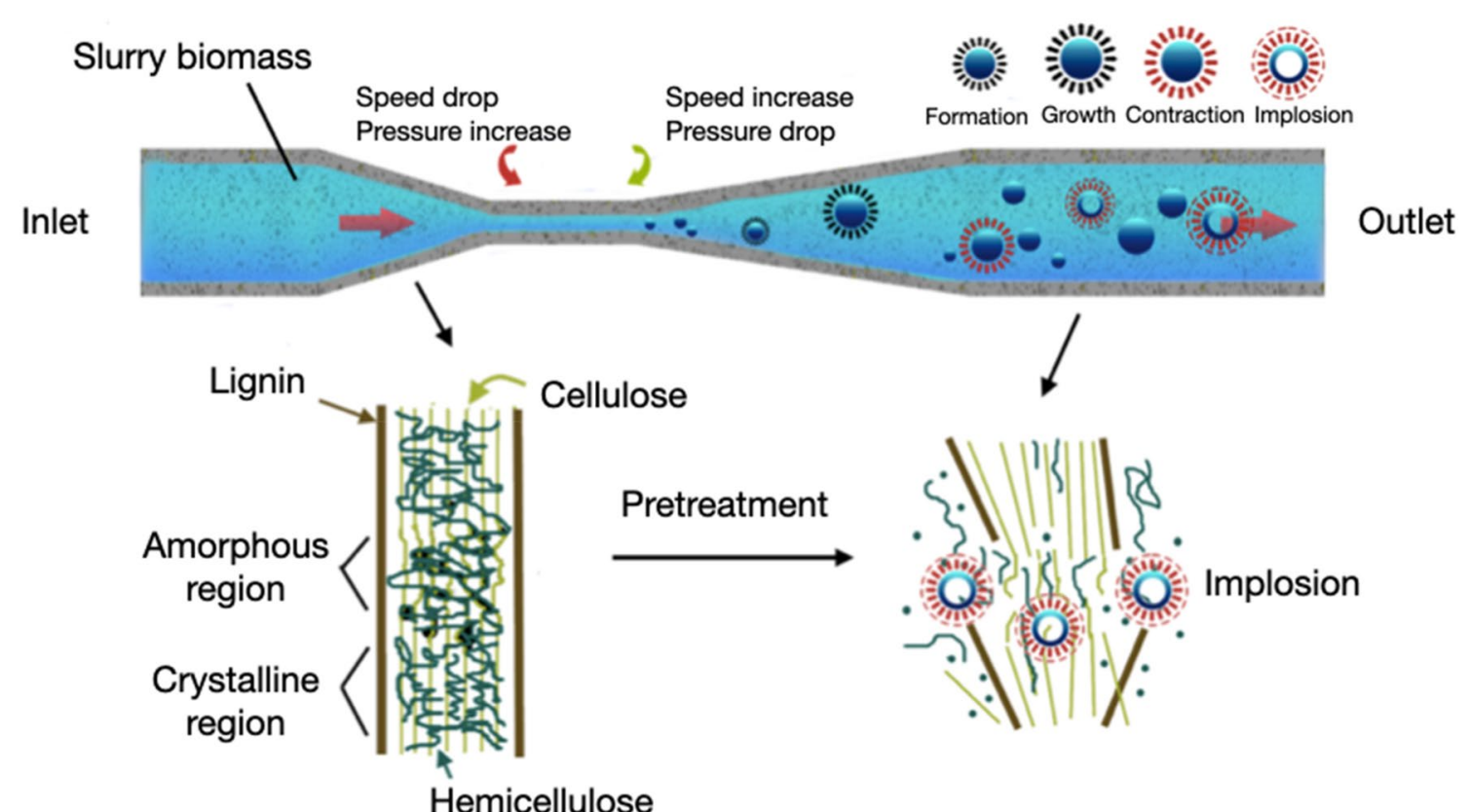

Fig. 2 Mechanical effect of hydrodynamic cavitation on lignocellulosic biomass pretreatment 


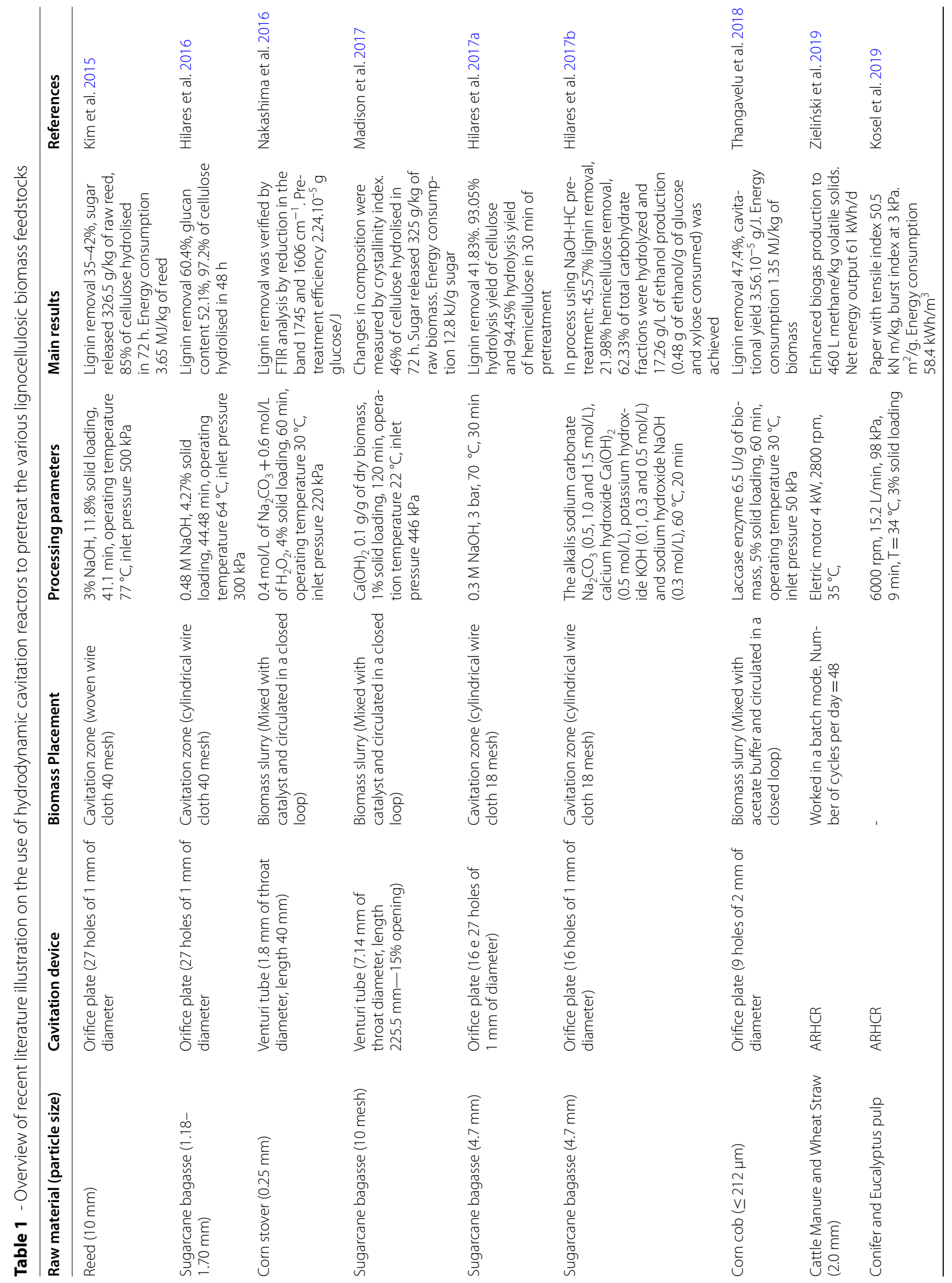




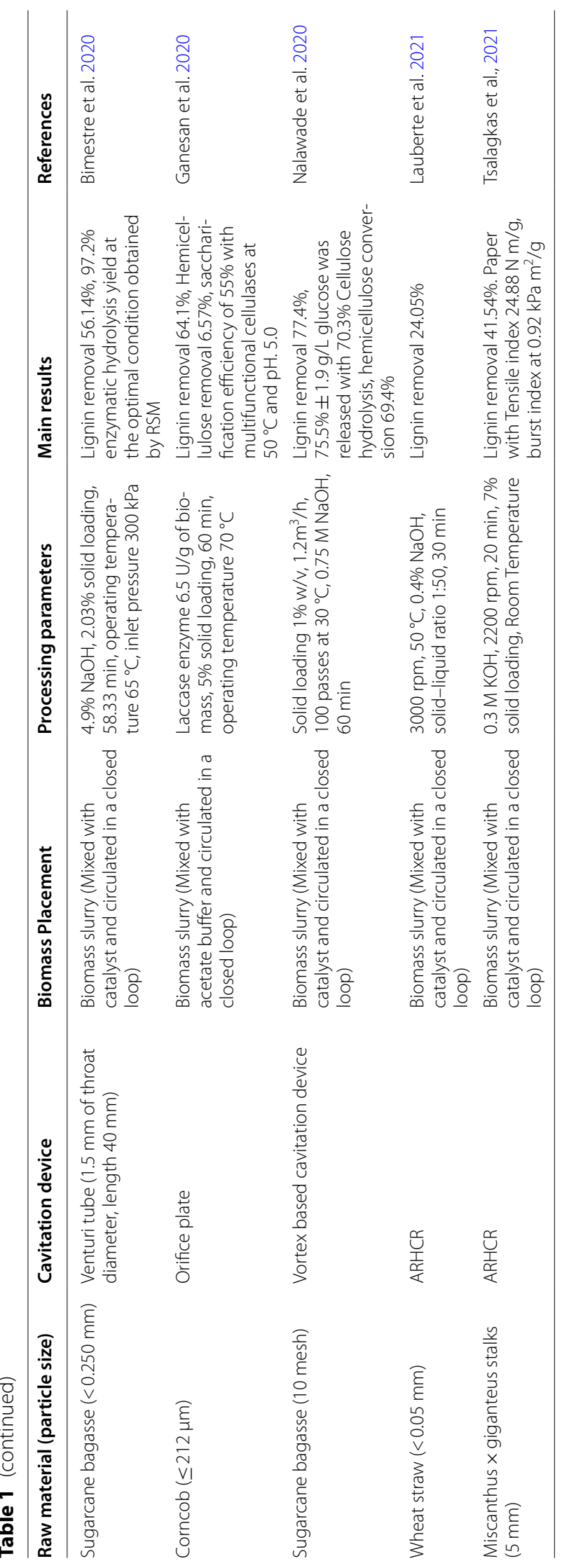


hydrodynamic cavitation (Venturi tube reactor) and alkaline sodium hydroxide solution $(5 \% \mathrm{w} / \mathrm{w})$. The rates of delignification obtained using hydrodynamic cavitation were about 4-5 orders of magnitude greater than those obtained using acoustic cavitation (rate constants for delignification were $9.78 \times 10^{-6}$ and $6.8 \times 10^{-1} / \mathrm{min}$ for acoustic and hydrodynamic cavitation, respectively).

A hydrodynamic cavitation is a versatile form of pretreatment that can be combined with other methods. Using the synergistic benefits of combined methods has been a new integrated pretreatment approach.

Badve et al. (2014) use hydrodynamic cavitation for intensification of the delignification of wheat straw as an essential step in the paper manufacturing process. Wheat straw was first treated with potassium hydroxide $(\mathrm{KOH})$ for $48 \mathrm{~h}$ and subsequently, alkali-treated wheat straw was subjected to hydrodynamic cavitation in an ARHCR. It has been observed that treatment of alkalitreated wheat straw in hydrodynamic cavitation reactor for 10-15 min increases the tensile index of the synthesized paper sheets to about $50-55 \%$, which is sufficient for paper board manufacture.

Kim et al. (2015) studied hydrodynamic cavitationassisted alkali pretreatment of reed. The cavitation device employed was an orifice plate with 27 holes of a $1 \mathrm{~mm}$ diameter. Reactional volume used was $150 \mathrm{~mL}$, with an inlet pressure of $500 \mathrm{kPa}$ at a work temperature of $77^{\circ} \mathrm{C}$. The optimal pretreatment condition was determined as $3 \% \mathrm{NaOH}, 11.8 \%$ solid load, and reaction time of $41.1 \mathrm{~min}$, with lignin removal of $35-42 \%$ and maximum glucose yield of $326.5 \mathrm{~g} / \mathrm{kg}$ of biomass after $72 \mathrm{~h}$ of enzymatic hydrolysis. The hydrodynamic cavitation as biomass pretreatment also proved to be benefit from an energetic viewpoint with energetic consumption of $3.65 \mathrm{MJ} / \mathrm{kg}$ of biomass, a significatively lower value compared with ultrasonic cavitation with a consumption of $14.4 \mathrm{MJ} / \mathrm{kg}$ of biomass performed under similar conditions.

Zielinski et al. (2019) monitored the small-scale agricultural biogas plant for biogas production from agricultural residues over a period of 330 days. As the feedstock contained lignocellulosic biomass, ultrasonic pretreatment, and hydrodynamic cavitation pretreatment were used. The final net energy output of agricultural biogas plant (ABP), ABP-Ultrasonic pretreatment, and ABP-Hydrodynamic cavitation pretreatment was, respectively, 56, 52, and $61 \mathrm{kWh} /$ day. Also, in previous works based only on electricity consumption, hydrodynamic cavitation pretreatment of lignocellulosic biomass proved to be more competitive than a microwave (Wu et al. 2019), ultraviolet (Rajoriya et al. 2019), and electric field (Jung et al. 2014).
The lignocellulosic biomass processing steps require operations to be carried out more efficiently from the point of view of energy consumption, processing and production time, the quality of the material produced, and through environmentally friendly processes.

In this sense, Hilares et al. (2016) used hydrodynamic cavitation to optimize the sugarcane bagasse alkaline pretreatment. Under optimized conditions $(0.48 \mathrm{M} \mathrm{NaOH}$, $4.27 \%$ solid loading, and $44.48 \mathrm{~min}$.) reported $52.1 \%$ of glucan content, $60.4 \%$ of lignin removal, and $97.2 \%$ enzymatic digestibility after $48 \mathrm{~h}$ of hydrolysis. Furthermore, the enzymatic hydrolysis of pretreated sugarcane bagasse presents a yield of $82 \%$ higher in relation to the bagasse hydrolysis without pretreatment and 30\% higher than pretreated bagasse with only alkali. These results suggest that biomass digestibility does not depend only on changes in the composition of the pretreated biomass but has a strong correlation with structural changes that can be attributed to increased biomass porosity due to the mechanical effects of cavitation, favoring the diffusion of enzymes in the substrate (Nakashima et al. 2016). In another study, Hilares et al. (2017a) evaluate the hydrodynamic cavitation using the surface response methodology varying parameters as inlet pressure (1-3 bar), temperature $\left(40-70{ }^{\circ} \mathrm{C}\right)$, and $\mathrm{NaOH}$ concentration $(0.1-$ $0.3 \mathrm{M})$. Under optimal conditions $\left(3 \mathrm{bar}, 70^{\circ} \mathrm{C}\right.$, and $0.3 \mathrm{M}$ $\mathrm{NaOH}$ ) were obtained, respectively, $93.05 \%$ and $94.45 \%$ of hydrolysis cellulose and hemicellulose yield in $30 \mathrm{~min}$ of pretreatment. The authors also conducted two new experiments, to optimize the results, achieving a significant reduction in the pretreatment time to $20 \mathrm{~min}$. with an alkali $(\mathrm{NaOH})$ load of $0.3 \mathrm{~mol} / \mathrm{L}$ in the first study (Hilares et al. 2017b) and reducing the amount of $0.29 \mathrm{M}$ $\mathrm{NaOH}$ with the addition of $0.78 \% \mathrm{v} / \mathrm{v} \mathrm{H}_{2} \mathrm{O}_{2}$ in the second study (Hilares et al. 2018), managing to reduce the pretreatment time to $10 \mathrm{~min}$.

To reduce the alkali consumption, the black liquor obtained after first HC pretreatment can be further reused in each additional batch with fresh lignocellulosic biomass. Hilares et al. (2017b) reported that about $80 \%$ and $70 \%$ of cellulose and hemicellulose hydrolysis yields were achieved in SCB pretreated with black liquor in nine successive repeated batches. This is an important result in terms of favoring the economic viability of pretreatment of lignocellulosic biomass, reducing solvent consumption.

In addition to this approach, the use of biocatalysts to remove recalcitrant fractions from lignocellulosic biomass can also be combined with hydrodynamic cavitation. Thangavelu et al. (2018) combined the hydrodynamic cavitation using an orifice plate with the enzymatic pretreatment for corncob to biofuel production. The most significatively parameters of the study were enzyme 
load (3-10 U g $\left.\mathrm{g}^{1}\right)$, solid load (2.5-5\%), and reaction time (5-60 min). On optimized conditions $\left(6.5 \mathrm{U} \mathrm{g}^{1}, 5 \%\right.$, and $60 \mathrm{~min}$ ) obtained $47.4 \%$ of lignin removal, cavitation yield of $3.56 .10^{-5} \mathrm{~g} / \mathrm{J}$, and energy consumption calculated at $1.35 \mathrm{MJ} / \mathrm{kg}$.

Considering the potential of hydrodynamic cavitation, different operating modes have been studied, such as semi-continuous and continuous, both interesting alternatives from the operational point of view for biorefineries and other industrial applications. These processes save time, energy, and operating costs compared to the batch process if we consider that the biomass does not recirculate in the reactor, being treated only once, ensuring greater productivity (Lee et al. 2015; Hilares et al. 2019). Some research on continuous pretreatment methods with potential large-scale applications has been reported by Chen et al. (2013), Choi and Oh (2012), Vandenbossche et al. (2016), and Han et al. (2013).

\section{Influencing parameters on hydrodynamic cavitation intensity to lignocellulosic biomass pretreatment}

Is essential the identification of vital process parameters and the comprehension of the influence of these parameters involved in physical and chemical mechanisms (Gogate and Patil 2015). The main influence parameters in a hydrodynamic cavitation reactor to lignocellulosic biomass pretreatment can be classified in three groups:

\section{Reactor structural characteristic (geometry of cavitation device)}

In cavitation devices with Venturi pipe, a narrower throat causes a greater pressure gradient and consequently stronger cavitation, resulting in greater pretreatment efficacy compared to a case with a wider throat. Nakashima et al. (2016) assessed the throat diameter Venturi pipe influence in corn stover pretreatment. In this study, the greater release of glucose of $4 \mathrm{~g} / \mathrm{L}$ in enzymatic hydrolysis was reached when the $1.4 \mathrm{~mm}$ throat diameter was employed with a cavitation number of 0.29 compared with the case of $1.8 \mathrm{~mm}$ throat diameter with cavitation number equal to 0.44 and glucose release of $3 \mathrm{~g} / \mathrm{L}$. The ratio of length and throat diameter $(l / d)$ is a parameter that plays an important role in cavities growth control and in its final collapse conditions, concluding that the increase in $l / d$ ratio slows down the pressure recovery on Venturi pipe (Simpson and Ranade 2019). In cavitation reactors of the Venturi type, the recovery pressure rate is controlled by its divergence angle. This angle should vary from $5.5^{\circ}$ to $7.5^{\circ}$ for a Venturi pipe applied to hydrodynamic cavitation, where the recovery pressure rate must be favorable. High divergence angle values lead to sudden expansion and hydraulic losses raise. The expansion induces a loss due to the flow separation on walls and a secondary turbulent flux in the tube divergent section (Ashrafizadeh and Ghassemi 2015).

In orifice plates, the number and diameter of the orifices are fundamental parameters also. An area increase of orifices can raise the cavitation number and consequently reduce the expected effects. Hilares et al. (2017a) verified the cavitation number reduction using orifice plates with 16 holes of $1 \mathrm{~mm}\left(\sigma_{c}=0.017\right)$ besides the high efficiency in sugarcane bagasse pretreatment in relation to plates with 27 holes of $1 \mathrm{~mm}\left(\sigma_{c}=0.048\right)$.

These results are in accordance with the proposal that sugarcane bagasse pretreatment presents high efficiency with a low cavitation number. In systems with orifice plates, the $\alpha$ and $\beta$ parameters need to be calculated (Sivakumar and Pandit 2002) is given as:

$$
\begin{aligned}
& \alpha=\frac{\text { total perimeter of the holes }}{\text { total area of opened }}=\frac{4}{d_{0}}\left[\mathrm{~mm}^{-1}\right] \\
& \beta=\frac{\text { Sum of the hole area(s)on the orifice plate }}{\text { cross sectional area of the pipe }}=n\left(\frac{d_{0}}{D}\right)^{2}
\end{aligned}
$$

where $d_{0}$ is the orifice diameter, $D$ is the pipe diameter and $n$ is the number of holes in the orifice plate. The $\beta$ value significatively influences the cavitation number. Lower values of $\beta$ result in lower cavitation numbers. Already the value of $\alpha$ depends on the number of orifices in the plate and its diameter. Hilares et al. (2020) observed that the reduction sugars released in pretreated sugarcane bagasse enzymatic hydrolysis were a linear function of geometrical parameters $\alpha$ (directly proportional) and $\beta$ (inversely proportional). Furthermore, smaller orifice diameters allow high-velocity flow, high-frequency turbulence, and greater shear area, which results in greater collapse pressure, eliminating posterior resistance to mass transfer moreover leading to higher process efficiency (Ghayal et al. 2013; Chuah et al. 2016).

For ARHCRs the intensity of cavitation depends on the rotation speed. Higher rotation speeds lead to a lower cavitation number and a consequent increase in cavitation intensity. With higher rotation speeds, turbulence intensity increases, thus increasing the intensity of the bubble collapse (Kosel et al. 2019; Petkovšek et al. 2015).

\section{Liquid media and biomass features}

To reach efficient hydrolysis, the use of synergic benefits of combined methods may be a new integrated lignocellulosic biomass pretreatment approach. Chemical products as sodium hydroxide $(\mathrm{NaOH})$ and lime $\left[\mathrm{Ca}(\mathrm{OH})_{2}\right]$ are being used in combined pretreatment of hydrodynamic cavitation of sugarcane bagasse and reed (Kim et al. 2015; Madison et al. 2017) and sodium 
percarbonate $\left(2 \mathrm{Na}_{2} \mathrm{CO}_{3}\right.$ e $\left.3 \mathrm{H}_{2} \mathrm{O}_{2}\right)$ in corn stover pretreatment (Nakashima et al. 2016). The use of mechanical strengths as hydrodynamic cavitation increases the chemical reagents efficiency in pretreatment with excellent effectiveness in lignocellulosic biomass delignification, silica removal, partial hemicellulose removal, and cellulose swelling, resulting in a substantial increase in fiber superficial area, porosity, and cristanility changes (Carvalho et al. 2016). The biomass particle size can also affect the pretreatment efficiency in hydrodynamic cavitation systems as the heat and mass transfer. A particle size reduction increases the exposed biomass superficial area, beyond favoring the heat and mass transfer resulting in higher total conversions (Khullar et al. 2013). In continuous pretreatment systems, where the powdered biomass is mixing with the catalyst forming a biomass slurry, which is pumping in a closed loop. In these systems, the particle size must be observed so that it does not occur clogging in the pump and cavitation device. An alternative solution to maintaining the biomass isolated in the cavitation zone avoiding the solid particle circulation on the orifices (Hilares et al. 2017a).

\section{Technological process features}

The liquid temperature is an important parameter, which can affect the cavitation efficiency. Vapor fluid pressure depends on temperature and increases exponentially with it. Besides, the solution properties as density, viscosity, and surface tension are affected too. That way increases the fluid temperature will result in a proportional increase in reaction velocity and cavitation effects. However, after reaching very high temperatures $\left(70{ }^{\circ} \mathrm{C}\right)$ the effects decrease (Šarc et al. 2018; Hilares et al. 2017a). As the effects of temperature on cavitation intensity for pretreatment of lignocellulosic biomass are contradictory at high temperatures, a compromise value must be obtained by optimization in real applications (Sun et al. 2021a).

Inlet pressure is an important parameter also because the developed vapor cavities depend on it. A pressure increase tends to turn vapor bubble collapse more violent, liberating a high number of radicals $\mathrm{OH}$ and reducing the cavitation number (Gogate and Patil 2015). Meanwhile, very high pressures on the inlet can cause the supercavitation phenomena which is a vapor cavities cloud formation whose collapse is significatively dampened leading to a decreasing cavitational effectivity. In general, inlet pressure values on 3-5 bar range have been considered ideal to Venturi pipe and orifice plates set up to hydrodynamic cavitation conditions applied to lignocellulosic biomass (Sharma et al. 2019; Hilares et al. 2016).
The duration of pretreatment is also an important parameter. Usually, longer durations are better for process efficiency. However, long times considerably increase the pretreatment costs and possibly generate more by-products for example inhibitors such as 5-hydroxymethylfurfural, furfural, phenolic acids, and aromatic compounds (Zhao et al. 2021; Parawira and Tekere 2011).

As observed are many factors that affect the performance and design of cavitation reactors. The optimization of these parameters can be done from the design of experiments (DOE), which is a statistical approach that allows the variation of different parameters at the same time. The most used method in the pretreatment of lignocellulosic biomass is the response surface methodology (RSM) whose objective is to optimize a response influenced by several factors (Nalawade et al. 2020; Bimestre et al. 2020; Hilares et al. 2020).

Due to the flow complexity and necessary measurement instrumentation to make experimental flow characterization, allied to complex geometry and low temporal scales the computational fluid dynamics can be an important tool in the cavitation reactors design (Abbas-Shiroodi et al. 2021).

\section{Hydrodynamic cavitation at industrial level}

Adaptation of hydrodynamic cavitation pretreatment to industrial level requires a lignocellulosic biomass sustainable conversion with costs minimization and process efficiency maximization. Hydrodynamic cavitation-based technology appears as a promising biomass pretreatment at industrial scales, which may be tailored to continuous or semi-continuous operation saving time, energy, and operational costs. The fact that hydrodynamic cavitation reactors have a simple setup, and are easily scalable if compared to other cavitation reactor options, can be installed in any existing production process as a separate module without major process modification (Sun et al. 2021a; Hirooka et al. 2009). Both combined methods and recycled chemical products usage aggregate environmental and sustainable economics to the process (Verdini et al. 2021).

Ramirez-Cadavid et al. (2014) used cavitation in a commercial-scale corn ethanol production process to release and hydrolyze unconverted carbohydrate fractions. The results show that cavitation altered the particle size distribution led to qualitative changes in cell structure, increased the total sugars after liquefaction, reduced the total solids after liquefaction, and led to significant increases in ethanol production and solids conversion during SSF. Simple energy and economic analysis showed that the energy return of cavitation in the form of ethanol is 16 times greater than the energy expended to generate the cavitation. Furthermore, the value of the extra 
ethanol produced by cavitation was 38 times more than the cost of the electricity used for the cavitation system.

Garuti et al. (2018) in a full-scale application of a hydrodynamic cavitation system in an agricultural biogas plant investigated the unique pretreatment without recirculation for enhancing the methane potential from agricultural biomasses with molasses and cornmeal as supplementary energy sources. In 6 months of operational data showed that pretreatment with hydrodynamic cavitation maximized specific methane production by about $10 \%$. Furthermore, hydrodynamic cavitation affected the viscosity and particle size of digestate, contributing to reduced energy demand for mixing, heating, and pumping.

\section{Future perspectives}

Hydrodynamic cavitation is an extremely complex phenomenon and, as such, its application in the pretreatment of lignocellulosic biomass has some limitations and challenges that should be addressed in future research.

It is essential to identify the vital parameters of the process and understand the influence of these parameters on the physical and chemical mechanisms involved, as well as their combined effects. The optimization of these parameters is extremely important for the method's viability. Transport properties of the reaction mixture, the heat and mass transfer of the system, the chemical kinetics of the reaction medium (Badve et al. 2015) in addition to the complexity and variability of the proportions of chemical structures in biomass that impact its biodegradability require further research and investigations.

The hydrodynamic cavitation-assisted biomass pretreatment process has some disadvantages related to the use of different chemicals and biomass recovery process. Furthermore, it uses large volumes of water to reach the required $\mathrm{pH}$ of the biomass for use in the subsequent steps of enzymatic hydrolysis and fermentation (Prado et al. 2021). Due to the strong collapse of cavitation bubbles, erosion and vibration problems in reactors can affect their durability and performance, requiring further investigations in this regard (Sun et al. 2021a).

Future investigations for hydrodynamic cavitation should be conducted with hydrogen peroxide (Valim et al. 2017) and ozone (Osório-González et al. 2020) beyond the Fenton reactions (Fenton reaction and Fenton-like reaction) releasing hydroxyl radicals $(\mathrm{OH})$ and hydroperoxyl $\left(\mathrm{HO}_{2}\right)$ oxidizing and degrading the recalcitrant structures of lignocellulosic biomass making easier the access of enzymes to cellulose and enhancing the enzymatic hydrolysis (Liu et al. 2020). An important aspect to be considered is the development of recovery and reuse strategies for the chemicals used, such as the coupling of alkali recovery membranes, as well as to valorize lignin-hemicellulose fractions or derivatives from the wastewater (Prado et al. 2021).

In addition, CFD computational fluid dynamics can be used from the conceptual phase of reactor design, helping to determine the best product solution until the production stage, allowing to represent of different scenarios. The use of advanced experiments such as highspeed photograph and particle image velocimetry should also be encouraged (Sun et al. 2021a).

More accurate studies of economic feasibility analysis with a survey of operating costs, maintenance, and investments in equipment are necessary.

\section{Conclusions}

This review highlighted the importance and hydrodynamic cavitation potential as an alternative to conventional methods of lignocellulosic biomass pretreatment. The reactor setup has a fundamental importance in the process as well as the operational conditions as temperature, inlet pressure, cavitation number, and particle size turning the process economically viable in the biorefinery context. Hydrodynamic cavitation has shown an excellent alternative to large-scale processing, friendly ecological, energetically efficient, and can be employed together with other pretreatment ways. Future investigations should concentrate on high-performance reactor design with low costs and combined pretreatment methods.

\section{Acknowledgements \\ This work greatly acknowledges Coordenação de Aperfeiçoamento de Pessoal de Nível Superior-Brasil (CAPES) and FEG/UNESP. \\ Authors' contributions \\ TAB — conceptualization, methodology, and writing (original draft prepara- tion). JAMJ—writing (original draft). EVC — writing —reviewing and editing CET-supervision. All authors read and approved the final manuscript.}

\section{Funding}

This study was financed in part by the Coordenação de Aperfeiçoamento de Pessoal de Nível Superior_Brasil (CAPES)_Finance code 001.

Availability of data and materials

The data supporting the conclusions are included in the main manuscript.

\section{Declarations}

Ethics approval and consent participate

Not applicable.

\section{Consent for publication}

All authors have read this article and have approved its submission to Bioresources and Bioprocessing.

\section{Competing interests}

The authors declare that they have no known competing financial interests or personal relationships that could have appeared to influence the work reported in this paper.

\section{Author details}

${ }^{1}$ Chemistry and Energy Department, School of Engineering, São Paulo State University UNESP, Guaratinguetá, SP 12516-410, Brazil. ${ }^{2}$ Center for Weather 
Forecasting and Climate Studies, National Institute for Space Research CPTEC/ INPE, Cachoeira Paulista, SP 12630-000, Brazil.

Received: 13 November 2021 Accepted: 18 January 2022 Published online: 25 January 2022

\section{References}

Abbas-Shiroodi Z, Sadeghi MT, Baradaran S (2021) Design and optimization of a cavitating device for Congo red decolorization: experimental investigation and CFD simulation. Ultrason Sonochem 71:105386. https://doi. org/10.1016/j.ultsonch.2020.105386

Abraham A, Mathew AK, Park H, Choi O, Sindhu R, Parameswaran B et al (2020) Pretreatment strategies for enhanced biogas production from lignocellulosic biomass. Biores Technol 301:122725. https://doi.org/10.1016/j. biortech.2019.122725

Abramov VO, Abramova AV, Cravotto G, Nikonov RV, Fedulov IS, Ivanov VK (2021) Flow-mode water treatment under simultaneous hydrodynamic cavitation and plasma. Ultrason Sonochem 70:105323. https://doi.org/ 10.1016/j.ultsonch.2020.105323

Arias P, Bellouin N, Coppola E, Jones R, Krinner G, Marotzke J et al (2021) Climate change 2021: the physical science basis contribution of working group 14 I to the sixth assessment report of the intergovernmental panel on climate change; technical summary. Soc Stud Sci. https://doi. org/10.1177/0306312720941933

Ashrafizadeh SM, Ghassemi H (2015) Experimental and numerical investigation on the performance of small-sized cavitating venturis. Flow Meas Instrum 42:6-15. https://doi.org/10.1016/j.flowmeasinst.2014.12.007

Badve M, Gogate P, Pandit A, Csoka L (2013) Hydrodynamic cavitation as a novel approach for wastewater treatment in wood finishing industry. Sep Purif Technol 106:15-21. https://doi.org/10.1016/j.seppur.2012.12. 029

Badve MP, Gogate PR, Pandit AB, Csoka L (2014) Hydrodynamic cavitation as a novel approach for delignification of wheat straw for paper manufacturing. Ultrason Sonochem 21(1):162-168. https://doi.org/10.1016/j. ultsonch.2013.07.006

Badve MP, Alpar T, Pandit AB, Gogate PR, Csoka L (2015) Modeling the shear rate and pressure drop in a hydrodynamic cavitation reactor with experimental validation based on KI decomposition studies. Ultrason Sonochem 22:272-277. https://doi.org/10.1016/j.ultsonch.2014.05.017

Bal M, Reddy TT, Meikap BC (2019) Removal of HCl gas from off gases using self-priming venturi scrubber. J Hazard Mater 364:406-418. https://doi. org/10.1016/j.jhazmat.2018.10.028

Banerjee S, Patti AF, Ranganathan V, Arora A (2019) Hemicellulose based biorefinery from pineapple peel waste: xylan extraction and its conversion into xylooligosaccharides. Food Bioprod Process 117:38-50. https://doi. org/10.1016/j.fbp.2019.06.012

Baxi PB, Pandit AB (2012) Using cavitation for delignification of wood. Biores Technol 110:697-700. https://doi.org/10.1016/j.biortech.2012.01.042

Bhowmick G, Sarmah AK, Sen R (2018) Lignocellulosic biorefinery as a model for sustainable development of biofuels and value added products. Biores Technol 247:1144-1154. https://doi.org/10.1016/j.biortech.2017. 09.163

Bimestre TA, Júnior JAM, Botura CA, Canettieri E, Tuna CE (2020) Theoretical modeling and experimental validation of hydrodynamic cavitation reactor with a Venturi tube for sugarcane bagasse pretreatment. Biores Technol 311:123540. https://doi.org/10.1016/j.biortech.2020.123540

Carvalho DM, de Queiroz JH, Colodette JL (2016) Assessment of alkaline pretreatment for the production of bioethanol from eucalyptus, sugarcane bagasse and sugarcane straw. Ind Crops Prod 94:932-941. https://doi. org/10.1016/j.indcrop.2016.09.069

Chen WH, Tsai CC, Lin CF, Tsai PY, Hwang WS (2013) Pilot-scale study on the acid-catalyzed steam explosion of rice straw using a continuous pretreatment system. Biores Technol 128:297-304. https://doi.org/10. 1016/j.biortech.2012.10.111

Chipurici P, Vlaicu A, Calinescu I, Vinatoru M, Vasilescu M, Ignat ND, Mason TJ (2019) Ultrasonic, hydrodynamic and microwave biodiesel synthesisa comparative study for continuous process. Ultrason Sonochem 57:38-47. https://doi.org/10.1016/j.ultsonch.2019.05.011
Chitsaz H, Omidkhah M, Ghobadian B, Ardjmand M (2018) Optimization of hydrodynamic cavitation process of biodiesel production by response surface methodology. J Environ Chem Eng 6(2):2262-2268. https://doi. org/10.1016/j.jece.2018.02.047

Choi CH, Oh KK (2012) Application of a continuous twin screw-driven process for dilute acid pretreatment of rape straw. Biores Technol 110:349-354. https://doi.org/10.1016/j.biortech.2012.01.075

Chuah LF, Yusup S, Abd Aziz AR, Bokhari A, Abdullah MZ (2016) Cleaner production of methyl ester using waste cooking oil derived from palm olein using a hydrodynamic cavitation reactor. J Clean Prod 112:45054514. https://doi.org/10.1016/j.jclepro.2015.06.112

Dastane GG, Thakkar H, Shah R, Perala S, Raut J, Pandit AB (2019) Single and multiphase CFD simulations for designing cavitating venturi. Chem Eng Res Des 149:1-12. https://doi.org/10.1016/j.cherd.2019.06.036

Dhanke PB, Wagh SM (2020) Intensification of the degradation of Acid RED-18 using hydrodynamic cavitation. Emerging Contaminants 6:20-32. https://doi.org/10.1016/j.emcon.2019.12.001

Ganesan M, Vinayakamoorthy RM, Thankappan S, Muniraj I, Uthandi S (2020) Thermotolerant glycosyl hydrolases-producing Bacillus aerius CMCPS1 and its saccharification efficiency on HCR-laccase (LCCH)-pretreated corncob biomass. Biotechnol Biofuels 13(1):1-14. https://doi.org/10. 1186/s13068-020-01764-2

Garuti M, Langone M, Fabbri C, Piccinini S (2018) Monitoring of full-scale hydrodynamic cavitation pretreatment in agricultural biogas plant. Biores Technol 247:599-609. https://doi.org/10.1016/j.biortech.2017. 09.100

Ghayal D, Pandit AB, Rathod VK (2013) Optimization of biodiesel production in a hydrodynamic cavitation reactor using used frying oil. Ultrason Sonochem 20(1):322-328. https://doi.org/10.1016/j.ultsonch.2012.07.009

Giri R, Sharma RK (2020) Fungal pretreatment of lignocellulosic biomass for the production of plant hormone by Pichia fermentans under submerged conditions. Bioresour Bioprocess 7:1-11. https://doi.org/10.1186/ s40643-020-00319-5

Gogate PR, Pandit AB (2001) Hydrodynamic cavitation reactors: a state of the art review. Rev Chem Eng 17(1):1-85. https://doi.org/10.1515/revce. 2001.17.1.1

Gogate PR, Patil PN (2015) Combined treatment technology based on synergism between hydrodynamic cavitation and advanced oxidation processes. Ultrason Sonochem 25:60-69. https://doi.org/10.1016/j.ultso nch.2014.08.016

Gostiša J, Širok B, Repinc SK, Levstek M, Stražar M, Bizjan B, Zupanc M (2021) Performance evaluation of a novel pilot-scale pinned disc rotating generator of hydrodynamic cavitation. Ultrason Sonochem 72:105431. https://doi.org/10.1016/j.ultsonch.2020.105431

Haldar D, Purkait MK (2021) A review on the environment-friendly emerging techniques for pretreatment of lignocellulosic biomass: mechanistic insight and advancements. Chemosphere 264:128523. https://doi.org/ 10.1016/j.chemosphere.2020.128523

Han M, Kang KE, Kim Y, Choi GW (2013) High efficiency bioethanol production from barley straw using a continuous pretreatment reactor. Process Biochem 48(3):488-495. https://doi.org/10.1016/j.procbio.2013.01.007

Hassan SS, Williams GA, Jaiswal AK (2018) Emerging technologies for the pretreatment of lignocellulosic biomass. Biores Technol 262:310-318. https://doi.org/10.1016/j.biortech.2018.04.099

Hilares RT, Dos Santos JC, Ahmed MA, Jeon SH, da Silva SS, Han JI (2016) Hydrodynamic cavitation-assisted alkaline pretreatment as a new approach for sugarcane bagasse biorefineries. Biores Technol 214:609614. https://doi.org/10.1016/j.biortech.2016.05.004

Hilares RT, de Almeida GF, Ahmed MA, Antunes FA, da Silva SS, Han Jl, Dos Santos JC (2017a) Hydrodynamic cavitation as an efficient pretreatment method for lignocellulosic biomass: a parametric study. Biores Technol 235:301-308. https://doi.org/10.1016/j.biortech.2017.03.125

Hilares RT, lenny JV, Marcelino PF, Ahmed MA, Antunes FA, da Silva SS, Dos Santos JC (2017b) Ethanol production in a simultaneous saccharification and fermentation process with interconnected reactors employing hydrodynamic cavitation-pretreated sugarcane bagasse as raw material. Biores Technol 243:652-659. https://doi.org/10.1016/j.biortech. 2017.06.159

Hilares RT, Ramos L, da Silva SS, Dragone G, Mussatto SI, Santos JCD (2018) Hydrodynamic cavitation as a strategy to enhance the efficiency of 
lignocellulosic biomass pretreatment. Crit Rev Biotechnol 38(4):483493. https://doi.org/10.1080/07388551.2017.1369932

Hilares RT, Dionízio RM, Prado CA, Ahmed MA, da Silva SS, Santos JC (2019) Pretreatment of sugarcane bagasse using hydrodynamic cavitation technology: semi-continuous and continuous process. Biores Technol 290:121777. https://doi.org/10.1016/j.biortech.2019.121777

Hilares RT, Dionízio RM, Muñoz SS, Prado CA, de Sousa Júnior R, da Silva SS, Santos JC (2020) Hydrodynamic cavitation-assisted continuous pre-treatment of sugarcane bagasse for ethanol production: effects of geometric parameters of the cavitation device. Ultrason Sonochem 63:104931. https://doi.org/10.1016/j.ultsonch.2019.104931

Hirooka K, Asano R, Yokoyama A, Okazaki M, Sakamoto A, Nakai Y (2009) Reduction in excess sludge production in a dairy wastewater treatment plant via nozzle-cavitation treatment: case study of an on-farm wastewater treatment plant. Biores Technol 100(12):3161-3166. https://doi. org/10.1016/j.biortech.2009.01.011

Ijiri M, Shimonishi D, Nakagawa D, Yoshimura T (2018) New water jet cavitation technology to increase number and size of cavitation bubbles and its effect on pure Al surface. Int J Lightweight Mater Manuf 1(1):12-20. https://doi.org/10.1016/.j.jlmm.2018.03.003

Jensen MB, Kofoed MVW, Fischer K, Voigt NV, Agneessens LM, Batstone DJ, Ottosen LDM (2018) Venturi-type injection system as a potential H2 mass transfer technology for full-scale in situ biomethanation. Appl Energy 222:840-846. https://doi.org/10.1016/j.apenergy.2018.04.034

Ji D, Zhang M, Xu T, Wang K, Li P, Ju F (2015) Experimental and numerical studies of the jet tube based on venturi effect. Vacuum 111:25-31. https:// doi.org/10.1016/j.vacuum.2014.09.010

Ji L, Zheng Z, Wu T, Xie Y, Liu Z, Huang G, Niu D (2020) Synergetic optimization management of crop-biomass coproduction with food-energy-water nexus under uncertainties. J Clean Prod 258:120645. https://doi.org/10. 1016/j.jclepro.2020.120645

Jung KW, Hwang MJ, Yun YM, Cha MJ, Ahn KH (2014) Development of a novel electric field-assisted modified hydrodynamic cavitation system for disintegration of waste activated sludge. Ultrason Sonochem 21(5):16351640. https://doi.org/10.1016/j.ultsonch.2014.04.008

Khullar E, Dien BS, Rausch KD, Tumbleson ME, Singh V (2013) Effect of particle size on enzymatic hydrolysis of pretreated Miscanthus. Ind Crops Prod 44:11-17. https://doi.org/10.1016/j.indcrop.2012.10.015

Kim I, Lee I, Jeon SH, Hwang T, Han JI (2015) Hydrodynamic cavitation as a novel pretreatment approach for bioethanol production from reed. Bioresour Technol 192:335-339. https://doi.org/10.1016/j.biortech.2015. 05.038

Kim H, Koo B, Sun X, Yoon JY (2020) Investigation of sludge disintegration using rotor-stator type hydrodynamic cavitation reactor. Sep Purif Technol 240:116636. https://doi.org/10.1016/j.seppur.2020.116636

Kleingesinds EK, José ÁH, Brumano LP, Silva-Fernandes T, Rodrigues D Jr, Rodrigues RC (2018) Intensification of bioethanol production by using Tween 80 to enhance dilute acid pretreatment and enzymatic saccharification of corncob. Ind Crops Prod 124:166-176. https://doi.org/ 10.1016/j.indcrop.2018.07.037

Kosel J, Šinkovec A, Dular M (2019) A novel rotation generator of hydrodynamic cavitation for the fibrillation of long conifer fibers in paper production. Ultrason Sonochem 59:104721. https://doi.org/10.1016/j. ultsonch.2019.104721

Koupaie EH, Dahadha S, Lakeh AB, Azizi A, Elbeshbishy E (2019) Enzymatic pretreatment of lignocellulosic biomass for enhanced biomethane production-a review. J Environ Manage 233:774-784. https://doi.org/ 10.1016/j.jenvman.2018.09.106

Kumar PS, Pandit AB (1999) Modeling hydrodynamic cavitation. Chem Eng Technol 22(12):1017-1027. https://doi.org/10.1002/(sici)15214125(199912)22:123.0.co;2-I

Kumar AK, Sharma S (2017) Recent updates on different methods of pretreatment of lignocellulosic feedstocks: a review. Bioresour Bioprocess 4(1):1-19. https://doi.org/10.1186/s40643-017-0137-9

Kumar B, Bhardwaj N, Agrawal K, Chaturvedi V, Verma P (2020) Current perspective on pretreatment technologies using lignocellulosic biomass: an emerging biorefinery concept. Fuel Proess Technol 199:106244. https://doi.org/10.1016/j.fuproc.2019.106244

Kumari D, Singh R (2018) Pretreatment of lignocellulosic wastes for biofuel production: a critical review. Renew Sustain Energy Rev 90:877-891. https://doi.org/10.1016/j.rser.2018.03.111
Lauberte L, Telysheva G, Cravotto G, Andersone A, Janceva S, Dizhbite T et al (2021) Lignin-derived antioxidants as value-added products obtained under cavitation treatments of the wheat straw processing for sugar production. J Clean Prod 303:126369. https://doi.org/10.1016/j.jclepro. 2021.126369

Lee J, Park KY (2020) Impact of hydrothermal pretreatment on anaerobic digestion efficiency for lignocellulosic biomass: Influence of pretreatment temperature on the formation of biomass-degrading byproducts. Chemosphere 256:127116. https://doi.org/10.1016/..chemosphere. 2020.127116

Lee SL, O'Connor TF, Yang X, Cruz CN, Chatterjee S, Madurawe RD et al (2015) Modernizing pharmaceutical manufacturing: from batch to continuous production. J Pharm Innov 10(3):191-199. https://doi.org/10.1007/ s12247-015-9215-8

Lee I, Oh YK, Han JI (2019) Design optimization of hydrodynamic cavitation for effectual lipid extraction from wet microalgae. J Environ Chem Eng 7(2):102942. https://doi.org/10.1016/j.jece.2019.1029

Li X, Li M, Pu Y, Ragauskas AJ, Klett AS, Thies M, Zheng Y (2018) Inhibitory effects of lignin on enzymatic hydrolysis: the role of lignin chemistry and molecular weight. Renew Energy 123:664-674. https://doi.org/10. 1016/j.renene.2018.02.079

Li M, Bussonnière A, Bronson M, Xu Z, Liu Q (2019) Study of Venturi tube geometry on the hydrodynamic cavitation for the generation of microbubbles. Miner Eng 132:268-274. https://doi.org/10.1016/j.mineng. 2018.11.001

Li C, Yang F, Huang Y, Huang C, Zhang K, Yan L (2020) Comparison of hydrodynamic and ultrasonic cavitation effects on soy protein isolate functionality. J Food Eng 265:109697. https://doi.org/10.1016/j.food eng.2019.109697

Liu W, Wu R, Hu Y, Ren Q, Hou Q, Ni Y (2020) Improving enzymatic hydrolysis of mechanically refined poplar branches with assistance of hydrothermal and Fenton pretreatment. Biores Technol 316:123920. https://doi.org/ 10.1016/j.biortech.2020.123920

Luo H, Gao L, Liu Z et al (2021) Prediction of phenolic compounds and glucose content from dilute inorganic acid pretreatment of lignocellulosic biomass using artificial neural network modeling. Bioresour Bioprocess 8:134. https://doi.org/10.1186/s40643-021-00488-x

Madison MJ, Coward-Kelly G, Liang C, Karim MN, Falls M, Holtzapple MT (2017) Mechanical pretreatment of biomass - part I: acoustic and hydrodynamic cavitation. Biomass Bioenerg 98:135-141. https://doi.org/10. 1016/j.biombioe.2017.01.007

Mahmood H, Moniruzzaman M, Iqbal T, Khan MJ (2019) Recent advances in the pretreatment of lignocellulosic biomass for biofuels and valueadded products. Curr Opin Green Sustain Chem 20:18-24. https://doi. org/10.1016/j.cogsc.2019.08.001

Mankar AR, Pandey A, Modak A, Pant KK (2021) Pre-treatment of lignocellulosic biomass: a review on recent advances. Biores Technol. https://doi.org/ 10.1016/j.biortech.2021.125235

Mevada J, Devi S, Pandit A (2019) Large scale microbial cell disruption using hydrodynamic cavitation: energy saving options. Biochem Eng J 143:151-160. https://doi.org/10.1016/j.bej.2018.12.010

Nakashima K, Ebi Y, Shibasaki-Kitakawa N, Soyama H, Yonemoto T (2016) Hydrodynamic cavitation reactor for efficient pretreatment of lignocellulosic biomass. Ind Eng Chem Res 55(7):1866-1871. https://doi.org/10. 1021/acs.iecr.5b04375

Nalawade K, Saikia P, Behera S, Konde K, Patil S (2020) Assessment of multiple pretreatment strategies for $2 \mathrm{G}$ L-lactic acid production from sugarcane bagasse. Biomass Convers Biorefin. https://doi.org/10.1007/ s13399-020-01163-5

Ong VZ, Wu TY, Chu KKL, Sun WY, Shak KPY (2021) A combined pretreatment with ultrasound-assisted alkaline solution and aqueous deep eutectic solvent for enhancing delignification and enzymatic hydrolysis from oil palm fronds. Ind Crops Prod 160:112974. https://doi.org/10.1016/j.inder op.2020.112974

Osorio-González CS, Hegde K, Brar SK, Vezina P, Gillbert D, Avalos-Ramírez A (2020) Pulsed-ozonolysis assisted oxidative treatment of forestry biomass for lignin fractionation. Biores Technol 313:123638. https://doi. org/10.1016/j.biortech.2020.123638

Panda D, Saharan VK, Manickam S (2020) Controlled hydrodynamic cavitation: a review of recent advances and perspectives for greener processing. Processes 8(2):220. https://doi.org/10.3390/pr8020220 
Parawira W, Tekere M (2011) Biotechnological strategies to overcome inhibitors in lignocellulose hydrolysates for ethanol production. Crit Rev Biotechnol 31(1):20-31. https://doi.org/10.3109/07388551003757816

Patil PN, Gogate PR, Csoka L, Dregelyi-Kiss A, Horvath M (2016) Intensification of biogas production using pretreatment based on hydrodynamic cavitation. Ultrason Sonochem 30:79-86. https://doi.org/10.1016/j.ultso nch.2015.11.009

Petkovšek M, Zupanc M, Dular M, Kosjek T, Heath E, Kompare B, Širok B (2013) Rotation generator of hydrodynamic cavitation for water treatment. Sep Purif Technol 118:415-423. https://doi.org/10.1016/j.seppur.2013. 07.029

Petkovšek M, Mlakar M, Levstek M, Stražar M, Širok B, Dular M (2015) A novel rotation generator of hydrodynamic cavitation for waste-activated sludge disintegration. Ultrason Sonochem 26:408-414. https://doi.org/ 10.1016/j.ultsonch.2015.01.006

Ponnusamy VK, Nguyen DD, Dharmaraja J, Shobana S, Banu JR, Saratale RG et al (2019) A review on lignin structure, pretreatments, fermentation reactions and biorefinery potential. Biores Technol 271:462-472. https://doi.org/10.1016/j.biortech.2018.09.070

Prado CA, Antunes FAF, Rocha TM, Sánchez-Muñoz S, Barbosa FG, Terán-Hilares $R$ et al (2021) A review on recent developments in hydrodynamic cavitation and advanced oxidative processes for pretreatment of lignocellulosic materials. Biores Technol. https://doi.org/10.1016/j.biort ech.2021.126458

Rai R, Bibra M, Chadha BS, Sani RK (2019) Enhanced hydrolysis of lignocellulosic biomass with doping of a highly thermostable recombinant laccase. Int J Biol Macromol 137:232-237. https://doi.org/10.1016/j.ijbio mac.2019.06.221

Rajoriya S, Bargole S, George S, Saharan VK, Gogate PR, Pandit AB (2019) Synthesis and characterization of samarium and nitrogen doped $\mathrm{TiO} 2$ photocatalysts for photo-degradation of 4-acetamidophenol in combination with hydrodynamic and acoustic cavitation. Sep Purif Technol 209:254-269. https://doi.org/10.1016/j.seppur.2018.07.036

Ramirez-Cadavid DA, Kozyuk O, Michel FC (2014) Improvement in commercial scale dry mill corn ethanol production using controlled flow cavitation and cellulose hydrolysis. Biomass Convers Bioref 4(3):211-224. https:// doi.org/10.1007/s13399-013-0103-5

Raut-Jadhav S, Badve MP, Pinjari DV, Saini DR, Sonawane SH, Pandit AB (2016) Treatment of the pesticide industry effluent using hydrodynamic cavitation and its combination with process intensifying additives (H2O2 and ozone). Chem Eng J 295:326-335. https://doi.org/10.1016/j. cej.2016.03.019

Renault H, Werck-Reichhart D, Weng JK (2019) Harnessing lignin evolution for biotechnological applications. Curr Opin Biotechnol 56:105-111. https://doi.org/10.1016/j.copbio.2018.10.011

Rezania S, Oryani B, Cho J, Talaiekhozani A, Sabbagh F, Hashemi B et al (2020) Different pretreatment technologies of lignocellulosic biomass for bioethanol production: an overview. Energy 199:117457. https://doi. org/10.1016/j.energy.2020.117457

Saharan VK (2016) Computational study of different venturi and orifice type hydrodynamic cavitating devices. J Hydrodyn 28(2):293-305. https:// doi.org/10.1016/s1001-6058(16)60631-5

Samani BH, Behruzian M, Najafi G, Fayyazi E, Ghobadian B, Behruzian A et al (2021) The rotor-stator type hydrodynamic cavitation reactor approach for enhanced biodiesel fuel production. Fuel 283:118821. https://doi. org/10.1016/j.fuel.2020.118821

Šarc A, Kosel J, Stopar D, Oder M, Dular M (2018) Removal of bacteria Legionella pneumophila, Escherichia coli, and Bacillus subtilis by (super) cavitation. Ultrason Sonochem 42:228-236. https://doi.org/10.1016/j.ultsonch. 2017.11.004

Sarker TR, Pattnaik F, Nanda S, Dalai AK, Meda V, Naik S (2021) Hydrothermal pretreatment technologies for lignocellulosic biomass: a review of steam explosion and subcritical water hydrolysis. Chemosphere 284:131372. https://doi.org/10.1016/j.chemosphere.2021.131372

Saxena S, Saharan VK, George S (2019) Modeling \& simulation studies on batch anaerobic digestion of hydrodynamically cavitated tannery waste effluent for higher biogas yield. Ultrason Sonochem 58:104692. https://doi. org/10.1016/j.ultsonch.2019.104692

Sharma A, Thakur M, Bhattacharya M, Mandal T, Goswami S (2019) Commercial application of cellulose nano-composites_-a review. Biotechnol Rep 21:e00316. https://doi.org/10.1016/j.btre.2019.e00316
Shrikant BR, Khambete AK (2017) Hydrodynamic cavitation: a novel treatment approach. Mater Today 4(9):9680-9684. https://doi.org/10.1016/j.matpr. 2017.06.246

Simpson A, Ranade VV (2019) Modeling hydrodynamic cavitation in venturi: Influence of venturi configuration on inception and extent of cavitation. AlChE J 65(1):421-433. https://doi.org/10.1002/aic.16411

Sivakumar M, Pandit AB (2002) Wastewater treatment: a novel energy efficient hydrodynamic cavitational technique. Ultrason Sonochem 9(3):123131. https://doi.org/10.1016/S1350-4177(01)00122-5

Sun X, Kang CH, Park JJ, Kim HS, Om AS, Yoon JY (2018a) An experimental study on the thermal performance of a novel hydrodynamic cavitation reactor. Exp Thermal Fluid Sci 99:200-210. https://doi.org/10.1016/j. expthermflusci.2018.02.034

Sun X, Park JJ, Kim HS, Lee SH, Seong SJ, Om AS, Yoon JY (2018b) Experimental investigation of the thermal and disinfection performances of a novel hydrodynamic cavitation reactor. Ultrason Sonochem 49:13-23. https:// doi.org/10.1016/j.ultsonch.2018.02.039

Sun X, Liu J, Ji L, Wang G, Zhao S, Yoon JY, Chen S (2020a) A review on hydrodynamic cavitation disinfection: the current state of knowledge. Sci Total Environ 737:139606. https://doi.org/10.1016/.jscitotenv.2020.139606

Sun X, Jia X, Liu J, Wang G, Zhao S, Ji L et al (2020b) Investigation on the characteristics of an advanced rotational hydrodynamic cavitation reactor for water treatment. Sep Purif Technol 251:117252. https://doi.org/10. 1016/j.seppur.2020.117252

Sun X, Liu S, Zhang X, Tao Y, Boczkaj G, Yoon JY, Xuan X (2021) Recent advances in hydrodynamic cavitation-based pretreatments of lignocellulosic biomass for valorization. Bioresour Technol. https://doi.org/10.1016/j. biortech.2021.126251

Sun X, Xuan X, Song Y, Jia X, Ji L, Zhao S et al (2021 b) Experimental and numerical studies on the cavitation in an advanced rotational hydrodynamic cavitation reactor for water treatment. Ultrason Sonochem 70:105311. https://doi.org/10.1016/j.ultsonch.2020.105311

Sun X, Yang Z, Wei X, Tao Y, Boczkaj G, Yoon JY et al (2021c) Multi-objective optimization of the cavitation generation unit structure of an advanced rotational hydrodynamic cavitation reactor. Ultrason Sonochem 80:105771. https://doi.org/10.1016/j.ultsonch.2021.105771

Sun X, You W, Xuan X, Ji L, Xu X, Wang G et al (2021d) Effect of the cavitation generation unit structure on the performance of an advanced hydrodynamic cavitation reactor for process intensifications. Chem Eng J 412:128600. https://doi.org/10.1016/j.cej.2021.128600

Thanekar P, Gogate PR (2019) Combined hydrodynamic cavitation based processes as an efficient treatment option for real industrial effluent. Ultrason Sonochem 53:202-213. https://doi.org/10.1016/j.ultsonch. 2019.01.007

Thangavelu K, Desikan R, Taran OP, Uthandi S (2018) Delignification of corncob via combined hydrodynamic cavitation and enzymatic pretreatment: process optimization by response surface methodology. Biotechnol Biofuels 11(1):1-13. https://doi.org/10.1186/s13068-018-1204-y

Tsalagkas D, Börcsök Z, Pásztory Z, Gogate P, Csóka L (2021) Assessment of the papermaking potential of processed Miscanthus $\times$ giganteus stalks using alkaline pre-treatment and hydrodynamic cavitation for delignification. Ultrason Sonochem 72:105462. https://doi.org/10.1016/j.ultso nch 2021.105462

Valim IC, Fidalgo JL, Rego AS, Vilani C, Martins ARF, Santos BF (2017) Neural network modeling to support an experimental study of the delignification process of sugarcane bagasse after alkaline hydrogen peroxide pre-treatment. Biores Technol 243:760-770. https://doi.org/10.1016/j. biortech.2017.06.029

Vandenbossche V, Brault J, Hernandez-Melendez O, Evon P, Barzana E, Vilarem G, Rigal L (2016) Suitability assessment of a continuous process combining thermo-mechano-chemical and bio-catalytic action in a single pilot-scale twin-screw extruder for six different biomass sources. Biores Technol 211:146-153. https://doi.org/10.1016/j.biortech.2016.03.072

Verdini F, Calcio Gaudino E, Grillo G, Tabasso S, Cravotto G (2021) Cellulose recovery from agri-food residues by effective cavitational treatments. Appl Sci 11(10):4693. https://doi.org/10.3390/app11104693

Waghmare A, Nagula K, Pandit A, Arya S (2019) Hydrodynamic cavitation for energy efficient and scalable process of microalgae cell disruption. Algal Res 40:101496. https://doi.org/10.1016/j.algal.2019.101496

Wang C, Jin R, He Z, Qiao Y, Wang Y, Wang K et al (2020) A new water treatment technology for degradation of $\mathrm{B}[\mathrm{a}] \mathrm{A}$ by hydrodynamic cavitation and 
chlorine dioxide oxidation. Ultrason Sonochem 61:104834. https://doi. org/10.1016/j.ultsonch.2019.104834

Wu Z, Tagliapietra S, Giraudo A, Martina K, Cravotto G (2019) Harnessing cavitational effects for green process intensification. Ultrason Sonochem 52:530-546. https://doi.org/10.1016/j.ultsonch.2018.12.032

Yiin CL, Yap KL, Ku AZE, Chin BLF, Lock SSM, Cheah KW et al (2021) Recent advances in green solvents for lignocellulosic biomass pretreatment: potential of choline chloride (ChCl) based solvents. Biores Technol. https://doi.org/10.1016/j.biortech.2021.125195

Zhao L, Sun ZF, Zhang CC, Nan J, Ren NQ, Lee DJ, Chen C (2021) Advances in pretreatment of lignocellulosic biomass for bioenergy production: challenges and perspectives. Biores Technol. https://doi.org/10.1016/j. biortech.2021.126123

Zheng Y, Zhao J, Xu F, Li Y (2014) Pretreatment of lignocellulosic biomass for enhanced biogas production. Prog Energy Combust Sci 42:35-53. https://doi.org/10.1016/j.pecs.2014.01.001

Zieliński M, Dębowski M, Kisielewska M, Nowicka A, Rokicka M, Szwarc K (2019) Cavitation-based pretreatment strategies to enhance biogas production in a small-scale agricultural biogas plant. Energy Sustain Dev 49:21-26. https://doi.org/10.1016/j.esd.2018.12.007

Zuin VG, Segatto ML et al (2018) Plants as resources for organic molecules: Facing the green and sustainable future today. Curr Opin Green Sustain Chem 9:1-7. https://doi.org/10.1016/j.cogsc.2017.10.001

\section{Publisher's Note}

Springer Nature remains neutral with regard to jurisdictional claims in published maps and institutional affiliations.

\section{Submit your manuscript to a SpringerOpen ${ }^{\circ}$ journal and benefit from:}

- Convenient online submission

- Rigorous peer review

- Open access: articles freely available online

- High visibility within the field

- Retaining the copyright to your article

Submit your next manuscript at $\boldsymbol{\nabla}$ springeropen.com 